\title{
Genetic Diversity and Relatedness Among Six Ranunculus Species Unraveled by SRAP Markers
}

\author{
Cristina D. KELEMEN ${ }^{1}$, Monica HÂRŢA ${ }^{2 *}$, Orsolya BORSAI ${ }^{1}$, Katalin $\mathrm{SZABO}^{2}$, Doina CLAPA ${ }^{2}$, Ladislav \\ KOKOSKA ${ }^{3}$, Doru PAMFIL ${ }^{1,2}$
}

\begin{abstract}
${ }^{1}$ Department of Horticulture and Landscaping, University of Agricultural Sciences and Veterinary Medicine Cluj-Napoca, 3-5 Mănăștur Street, Cluj-Napoca Romania

${ }^{2}$ University of Agricultural Sciences and Veterinary Medicine Cluj-Napoca, Life Sciences Institute, Research Centre for Agricultural Biotechnology affiliated at Romanian Academy, 3-5 Mănăştur Street, Cluj-Napoca, Romania

${ }^{3}$ Department of Crop Sciences and Agroforestry, Czech University of Life Sciences Prague, Kamycka 12916521 Prague 6-Suchdol, Czech Republic

*corresponding author: monica_bodea@hotmail.com
\end{abstract}

Bulletin UASVM Horticulture 75(2) / 2018

Print ISSN 1843-5262, Electronic ISSN 1843-536X

DOI:10.15835/buasvmcn-hort: 2018.0032

\begin{abstract}
The main aim of this study was to investigate the genetic diversity and phylogenetic relationships of six Ranunculus species using SRAP markers. The genotyping of 73 Ranunculus accessions showed that 12 primer pairs generated a total number of 212 polymorphic fragments with a $99.53 \%$ level of polymorphism. Nei's gene diversity ranged between 0.2237 and 0.3436 with an average of 0.3001 . The UPGMA method with Nei72's similarity coefficient ranging from 0.23 to 1.11 separated 73 accessions into two distinct groups (A and B). Cluster-A included $R$. acris members, while cluster-B included the rest of the tested species. Cluster-B was subsequently divided into two sub-groups (I and II). Subgroup-I consisted of $R$. carpaticus and R. serpens subsp. nemorosus accessions, while subgroup-II included the members of $R$. platanifolius, $R$. polyanthemos, and $R$. repens. $R$. polyanthemos and $R$. repens were founded the most closely related species. These findings provide a brand-new understanding of the evolutionary relationships of above mentioned Ranunculus species and may be useful tools for plant breeding and conservation purposes.
\end{abstract}

Keywords: Ranunculus; genetic variation, genetic resources, phylogeny, sequence-related amplified polymorphism marker (SRAP)

\section{Introduction}

In the last few years, awareness of the importance of adopting a holistic view of biodiversity conservation and sustainable use the natural resources has been increasing. Plant genetic resources are among the most crucial natural resources of the world, thus their conservation is essential for present and future human well-being (Rao and Hodgkin 2002). Because of the differences in evolutionary rates, plant DNA sequences can be used to examine taxonomy, origin, and the evolution of plant species (Rao and Hodgkin 2002). Moreover, analyses regarding genetic diversity and structure at intraand inter-specific level are especially important for a better use of genetic resources in breeding and conservation strategies of wild plants (Hamrick and Godt, 1996). Molecular markers have been increasingly used as an important tool to evaluate genetic variability and genetic relationships among various plant species including many of the Ranunculaceae family (Idrees and Irshad, 2014; Li et al., 2013; Paun et al., 2005).

Ranunculaceae Juss. (buttercup family) is one of the early lineages in flowering plants, being characterized by hypogynous flowers with 
numerous stamens, including approximately 59 genera and 2500 species (Heywood, Brummitt, Culham 2007). The most representative genera of the buttercup family are Aconitum, Anemone, Clematis, Delphinium, Ranunculus, and Thalictrum which constitutes approximately $90 \%$ of the species (Heywood et al., 2007).

Ranunculus L. (buttercups) represents the largest genus within the Ranunculaceae family, including ca. 600 species spread worldwide, but most commonly occurs in the temperate and cold areas of the northern hemisphere (Dochev et al., 2014). Buttercups are established in various terrestrial or aquatic habitats from lowlands to high alpine zones, and terrestrial species are often specialized in extreme, mainly cold/humid, but sometimes also xeric conditions (Hörandl et al., 2005). Various morphological adaptations and different reproductive strategies such as vegetative reproduction, self-compatibility, and agamospermy might be important factors for the ability of the species to colonize habitats at higher altitudes and latitudes (Hörandl et al., 2005). From a genetic point of view, an important character for the genus is the presence of the Ranunculus type (R-type) chromosome (c.3-12 $\mu \mathrm{m}$ long). The basic chromosome numbers of Ranunculus taxa are $\mathrm{x}=8$ (e.g. $R$. cantoniensis, $R$. quelpaertensis, and $R$. ternatus) or $\mathrm{x}=7$ (e.g. $R$. crucilobus, $R$. japonicus, and R. sceleratus) (Chung et al., 2013). Considering the two potential basic chromosome numbers, aneuploidy might have played an important role for lineage diversification in the genus. Moreover, different polyploidy levels together with autopolyploidy and allopolyploidy have been reported for many species of the genus, which might have had a major contribution to lineage speciation (Inceer et al., 2007; Hörandl et al., 2005). In addition, most of the species of the genus are rich in a broad variety of chemical components such as alkaloids and lactones, including anemonin, isoranunculin, protoanemonin, and ranunculin which can also be found in Ranunculus species (Hao et al. 2015a). Due to the presence of various medicinal phytometabolites, many Ranunculus species have been used for centuries as medicines, spices, and vegetables after cautious processing to reduce their toxicity (Hao et al., 2015). Many species of the genus have been characterized as an analgesic, antibacterial, anti-inflammatory, and antitumor agents (Hao et al., 2015)
In Romania the Ranunculus genus is represented by ca. 35 species spread all around the country (Cristea, 2014). Many local species of the genus have economic importance. They have been used as medicinals, insecticides, ornamentals and some are locally consumed as food (eg. R. ficaria) (Săvulescu, 2010). In traditional medicine, local species of Ranunculus have been used to treat various ailments such as arthritis, bronchitis, cough, fever, gout, neuralgia pains, rheumatism, ulcer and skin diseases (Alexan et al., 1991; Tămaș, 2005). However, little is known concerning the genetic variation and phylogeny of Ranunculus species from Romania. Previous molecular studies carried out on phylogenetic relationships of various species and accessions of Ranunculus has been attempted using isozyme (Suranto, 2002), ITS markers (Emadzade et al., 2010; Paun et al., 2005; Hörandl et al., 2005), microsatellite markers (Florence et al., 2007), RAPD markers (Fischer et al. 2000) and rbcL sequences of chloroplast DNA (Cai et al., 2010). Besides these, to the best of our knowledge no other reports on genetic variation and phylogenetic analysis of Ranunculus species using sequence-related amplified polymorphism (SRAP) markers. Therefore, the main aim of this study was to investigate the genetic diversity and phylogenetic relationships in six Ranunculus species using SRAP markers, to establish future breeding and conservation strategies for these plants. SRAP primers proved to be suitable for genetic diversity and phylogenetic analyses among related species and could generate more polymorphic fragments than simple sequence repeats (SSR), inter-simple sequence repeat (ISSR), or RAPD markers (Budak et al., 2004; Talebi et al., 2012; Zhang et al., 2014).

\section{Materials and Methods}

\section{Plant material}

A total of 75 Ranunculus accessions belonging to six species namely $R$. acris, $R$. carpaticus, $R$. platanifolius, R. polyanthemos, $R$. repens and $R$. serpens subsp. nemorosus were investigated in this study. Plant samples were collected from their natural habitats in July and August 2016 in two counties from Romania (Brașov and Hunedoara), namely at Mt. Postavaru and Mt. Stamba. The voucher specimens have been stored in the Herbarium collection at the University of Agricultural Sciences and Veterinary Medicine 
Table 1. Ranunculus accessions used in this study, voucher specimen number and origin of tested species

\begin{tabular}{|c|c|c|c|}
\hline Plant species & Plant number & $\mathrm{HSV}^{*}$ & Site location \\
\hline R. acris L. & 9 & CLA30042 & $46^{\circ} 12^{\prime} 50.8^{\prime \prime} \mathrm{N}, 22^{\circ} 51^{\prime} 35.4^{\prime \prime} \mathrm{E}$ \\
\hline R. carpaticus Herbich & 14 & CLA30044 & $45^{\circ} 34^{\prime} 56.1^{\prime \prime} \mathrm{N}, 25^{\circ} 33^{\prime} 21.7^{\prime \prime} \mathrm{E}$ \\
\hline R. platanifolius L. & 14 & CLA30040 & $45^{\circ} 34^{\prime} 56.1^{\prime \prime} \mathrm{N}, 25^{\circ} 33^{\prime} 21.7^{\prime \prime} \mathrm{E}$ \\
\hline R. polyanthemos L. & 14 & CLA30051 & $46^{\circ} 12^{\prime} 50.8^{\prime \prime} \mathrm{N}, 22^{\circ} 51^{\prime} 35.4^{\prime \prime} \mathrm{E}$ \\
\hline R. repens L. & 14 & CLA30045 & $46^{\circ} 12^{\prime} 50.8^{\prime \prime} \mathrm{N}, 22^{\circ} 51^{\prime} 35.4^{\prime \prime} \mathrm{E}$ \\
\hline R. serpens subsp. nemorosus L. & 10 & CLA 30043 & $45^{\circ} 34^{\prime} 56.1^{\prime \prime} \mathrm{N}, 25^{\circ} 33^{\prime} 21.7^{\prime \prime} \mathrm{E}$ \\
\hline Total number of accessions & 75 & - & - \\
\hline
\end{tabular}

Table 2. The forward and reverse SRAP primer used in this study

\begin{tabular}{llll}
\hline & Forward primers & & \multicolumn{1}{l}{ Reverse primers } \\
\hline Me1 & F: TGA GTC CAA ACC GGA TA & Em1 & R: GAC TGC GTA CGA ATT AAT \\
\hline Me3 & F: TGA GTC CAA ACC GGA AT & Em3 & R: GAC TGC GTA CGA ATT GAC \\
\hline Me4 & F: TGA GTC CAA ACC GGA CC & Em4 & R: GAC TGC GTA CGA ATT TGA \\
\hline Me5 & F: TGA GTC CAA ACC GGA AG & Em5 & R: GAC TGC GTA CGA ATT AAC \\
\hline Me6 & F: TGA GTC CAA ACC GGA CA & Em6 & R: GAC TGC GTA CGA ATT GCA \\
\hline Me8 & F: TGA GTC CAA ACC GGA CT & Em7 & R: GAC TGC GTA CGA ATT CAA \\
\hline
\end{tabular}

of Cluj-Napoca, Romania. The leaves were air dried at room temperature and stored at $-20^{\circ} \mathrm{C}$ until further processing. The list of the accession number used for each species, voucher specimen number and origin of tested samples are provided in Table 1.

\section{DNA extraction}

The total genomic DNA was isolated from young leaves by applying the hexadecyltrimethylammonium bromide (CTAB), method as described by Lodhi et al. (1994) and improved by Pop et al. (2003). The quality and quantity of genomic DNA were estimated by measuring the absorbance at 260 and $280 \mathrm{~nm}$ using a NanoDrop, ND100 spectrophotometer. The concentration of DNA samples was adjusted at $50 \mathrm{ng} / \mathrm{L}$ and stored at $-20{ }^{\circ} \mathrm{C}$ until future analysis.

\section{SRAP reactions}

SRAP analysis was carried out according to previously established protocols of $\mathrm{Li}$ and Quiros (2001). A total of 64 SRAP primer pairs from eight forward and eight reverse primers were preliminary screened two times on one selected accession of $R$. carpaticus and $R$. platanifolius to test the ability of primer pairs to amplify DNA fragments. The twelve most reliable primers combinations that produced scorable polymorphic bands were used to amplify the rest of the accessions. The sequences of six forward and seven reverse SRAP primers used in this study are listed in Table 2.

Polymerase chain reaction was performed in $15 \mu \mathrm{L}$ reaction mixture containing $1 \times$ Green Buffer, $1.5 \mathrm{mM} \mathrm{MgCl2}, 200 \mu \mathrm{M}$ of dNTPs, 0.3 $\mu \mathrm{M}$ of both forward and reverse primer (Generi Biotech), $1 \mathrm{U}$ of Taq DNA polymerase (Promega) and approximately $50 \mathrm{ng}$ of template DNA. Amplifications were carried out in a Corbette Research PalmCycler (Corbett Research) with an initial step at $94^{\circ} \mathrm{C}$ for $5 \mathrm{~min}$, and five cycles of $1 \mathrm{~min}$ at $94^{\circ} \mathrm{C}, 1 \mathrm{~min}$ at $35^{\circ} \mathrm{C}$, and $1 \mathrm{~min}$ at $75^{\circ} \mathrm{C}$. The following 35 cycles consisted of $94{ }^{\circ} \mathrm{C}$ for $1 \mathrm{~min}, 50^{\circ} \mathrm{C}$ for $1 \mathrm{~min}$, and $72{ }^{\circ} \mathrm{C}$ for $1 \mathrm{~min}$, with a final extension at $72{ }^{\circ} \mathrm{C}$ for $10 \mathrm{~min}$. The PCR reactions were repeated to ensure reproducibility. Amplified products were separated on $1.6 \%$ $(\mathrm{w} / \mathrm{v})$ agarose gels in $1.0 \times$ TAE buffer, at $115 \mathrm{~V}$, for approximately 2 hours. The gel was stained with $1 \mu \mathrm{g} / \mathrm{mL} \mathrm{EtBr}$ for 20 to 30 minutes and the image was taken under UV light with Biospectrum AC for further analysis. A 100 bp DNA ladder was 

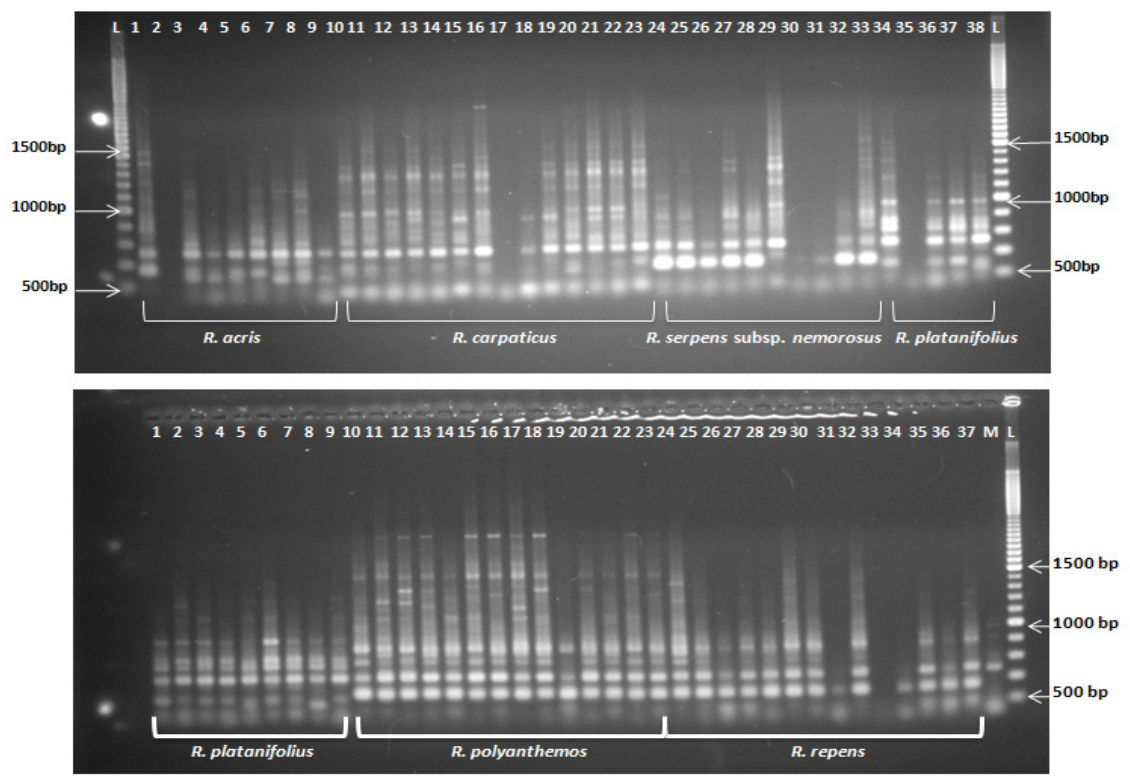

Figure 1. Electrophoresis profile of Ranunculus accessions obtained with Me1/Em3 SRAP primer combination (Lane L-100 bp DNA step Ladder; L1-L38/ L1-L37 Ranunculus samples; M-negativ control)

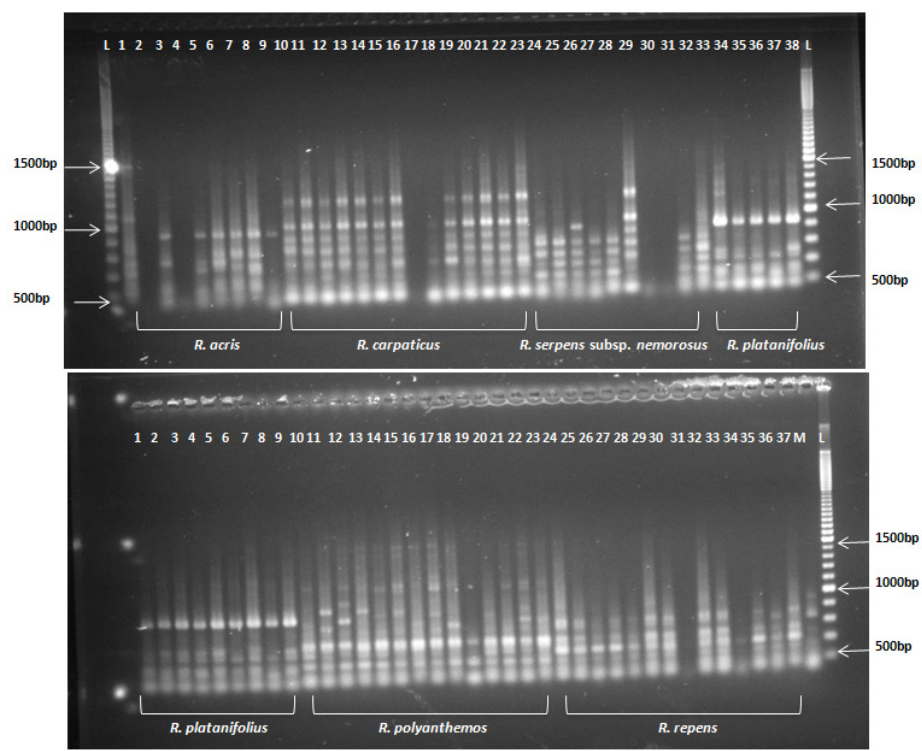

Figure 2. Electrophoresis profile of Ranunculus accessions obtained with Me6/Em5 SRAP primer combination (Lane L-100 bp DNA step Ladder; L1-L38/ L1-L37 Ranunculus samples; M-negativ control)

used as molecular standard in order to confirm the appropriate SRAP markers.

\section{Data analysis}

Each band was scored visually for their presence (1) or absent (0), twice for each accession using Total Lab 120 software. Only reproducible and clear DNA fragments were used for scoring. The data were compiled in a binary data matrix using Microsoft Excel and analyzed using the Numerical Taxonomy Multivariate Analysis System (NTSYS-pc 2.1) software package (Rohlf, 2000). The genetic distances were calculated using Nei72 similarity coefficient (Nei and Li, 1979) and a UPGMA dendrogram was constructed based on a symmetric dissimilarity matrix using the SHAN module in NTSYS pc 2.1. The COPH and MXCOP modules of NTSYS pc 2.1 were used to check the goodness-of-fit between the cluster analysis and dissimilarity matrix. The representativeness of dendrograms was evaluated by estimating cophenetic correlation for the dendrogram and comparing it with the similarity matrix, using Mantel's matrix correspondence test (Mantel, 1967). The result of this test is a cophenetic 
Table 3. Polymorphisms detected by SRAP primer pairs among 73 Ranunculus accessions

\begin{tabular}{|c|c|c|c|c|c|}
\hline Primer pairs & $\begin{array}{c}\text { Total bands } \\
\text { effective }\end{array}$ & $\begin{array}{l}\text { Polymorphic } \\
\text { alleles }\end{array}$ & $\begin{array}{c}\text { Effective allele } \\
\text { number (ne) }\end{array}$ & $\begin{array}{c}\text { Nei's gene diversity } \\
(\mathrm{He})\end{array}$ & $\begin{array}{c}\text { Shannon's information } \\
\text { index (I) }\end{array}$ \\
\hline Me1/Em3 & 16 & 16 & 15.501 & 0.3308 & 0.5030 \\
\hline Me1/Em7 & 21 & 21 & 14.516 & 0.2888 & 0.4516 \\
\hline $\mathrm{Me} 3 / \mathrm{Em} 3$ & 13 & 13 & 13.498 & 0.2353 & 0.3826 \\
\hline Me3/Em5 & 14 & 14 & 13.331 & 0.2237 & 0.3654 \\
\hline $\mathrm{Me} 4 / \mathrm{Em} 7$ & 15 & 15 & 15.580 & 0.3322 & 0.5023 \\
\hline Me5/Em5 & 16 & 16 & 14.976 & 0.2976 & 0.4572 \\
\hline Me6/Em4 & 15 & 15 & 15.725 & 0.3325 & 0.4970 \\
\hline Me6/Em6 & 16 & 15 & 14.826 & 0.2998 & 0.4596 \\
\hline Me8/Em1 & 35 & 35 & 14.750 & 0.2997 & 0.4651 \\
\hline Me8/Em5 & 19 & 19 & 14.542 & 0.2907 & 0.4567 \\
\hline Me8/Em6 & 22 & 22 & 15.201 & 0.3270 & 0.5020 \\
\hline Me8/Em8 & 11 & 11 & 15.734 & 0.3436 & 0.5196 \\
\hline Total & 213 & 212 & - & - & - \\
\hline Mean & 17.75 & 17.67 & 14.848 & 0.3001 & 0.4635 \\
\hline
\end{tabular}

correlation coefficient, $r$, indicating how well dendrogram represents similarity data.

The principal coordinate analysis (PCoA) of the original binary data matrix and based on Jaccard coefficient was performed using the DCENTER and EIGEN modules of NTSYS pc 2.1, in order to examine the relationships and differentiations between tested accessions. Effective allele number (ne), Nei's gene diversity (He) and Shannon's information index (I) were used to compute Nei's standard genetic distance coefficients using the Popgene32 program.

\section{Results and Discussion}

\section{SRAP analysis}

Twelve primer combinations were selected based on their clarity, sharpness and number of bands produced in a pre-screening assay carried out with 64 primer combinations, on two accessions. The most efficient primer combinations were $M e 3 / E m 3, M e 8 / E m 1, M e 8 /$ Em5 and Me8/Em6. Two accessions out of the 75 tested (one for $R$. carpaticus and one for $R$. serpens subsp. nemorosus) did not amplify with any of the primer combinations employed, therefore these members were excluded from the study.

The selective SRAP primer combinations (12) generated a total number of 213 reproducible fragments, ranging in size from 500 to 2200 bp. The number of bands scored per primer combination ranged from 11 to 35 , with a mean of 17.7. The highest number (35) of the amplification products was obtained using the Me8/Em1 primer pairs and the lowest (11) with $M e 8 / E m 8$. The electrophoresis profile of 75 Ranunculus accessions using SRAP primer combinations $\mathrm{Me1/}$ Em 3 and Me6/Em5 is shows in the Figure 1 and 2.

A number of 212 fragments were polymorphic, showing a $99.53 \%$ level of polymorphism in average. The effective allele number (ne) ranged from 1.3330 to 1.5734 with an average of 1.4848 , Nei's gene diversity (He) ranged between 0.2237 and 0.3436 with an average of 0.3001 , and Shannon's information index (I) varied between 0.3654 and 0.5196 with an average of 0.4635 (Table 3).

\section{Phylogenetic analysis}

The similarity dendrogram of the tested Ranunculus accessions was constructed using UPGMA cluster method based on Nei72's similarity coefficient (Fig. 3). The accessions studied had genetic similarity coefficients ranging from 0.23 to 1.11 with an average of 0.67 , indicating a high level of variation. Furthermore, the cophenetic correlation ( 0.84 value of the $r$ coefficient) indicates a good fit between the original similarity matrix and the built dendrogram.

UPGMA cluster analysis grouped all the 73 Ranunculus accessions into two major groups (marked A and B). Cluster-A included nine $R$. 


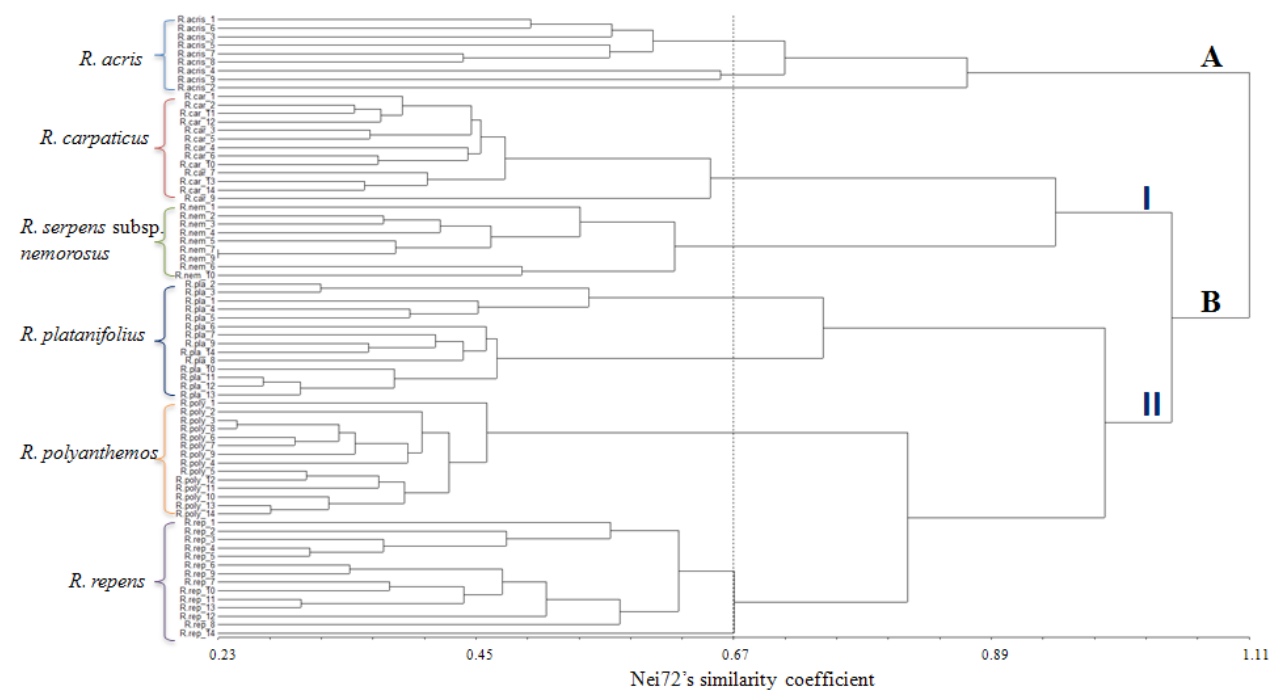

Figure 3. UPGMA dendrogram of 73 Ranunculus genotypes based on SRAP-based genetic similarities

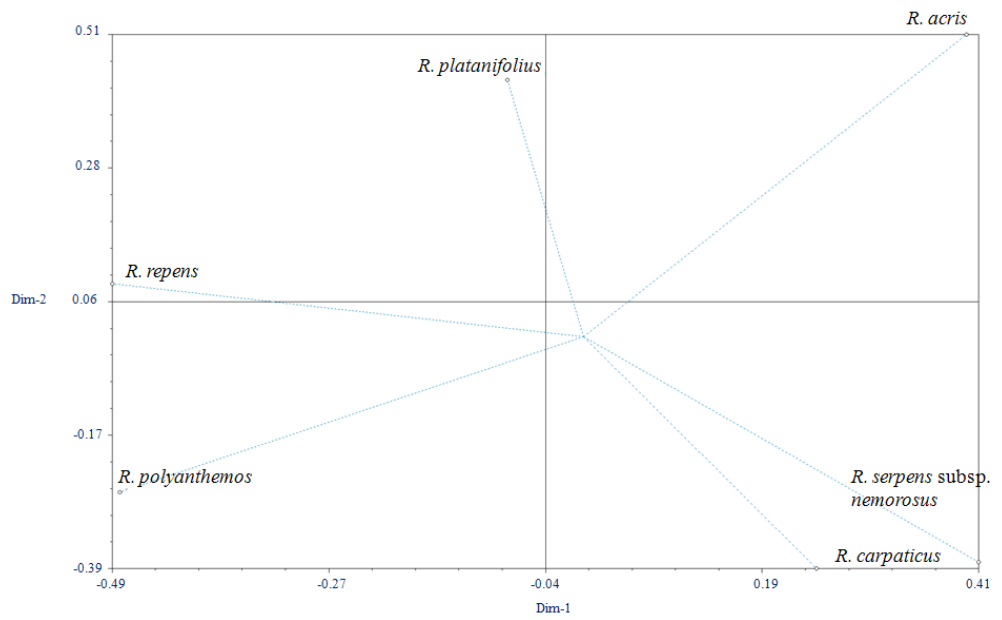

Figure 4. Relationships among Ranunculus species visualized by SRAP markers-based PCoA

acris members while cluster-B included the rest of the Ranunculus species tested (Fig. 3). This is in accordance with the results obtained by Paun et al. (2005) and Hörandl et al. (2005), where $R$. acris has been revealed as distinct species and was closely related to $R$. lanuginosus, $R$. japonicus, and $R$. grandiflorus. Moreover, cluster-B could be further divided into two sub-groups (I and II). Subgroup-I consisted of thirteen accessions of $R$. carpaticus and nine of $R$. serpens subsp. nemorosus, while subgroup-II included the fourteen accessions of $R$. platanifolius, $R$. polyanthemos, and $R$. repens, respectively. Furthermore, $R$. platanifolius has been revealed as a distinct species and formed an intermediate group. Regarding subgroup II, it is noteworthy that $R$. polyanthemos and $R$. repens were determined to be the most closely related species with a similarity level of 0.73 . In contrast to our findings, Paun et al. (2005) reported a great similarity between $R$. polyanthemos and $R$. serpens subsp. nemorosus taxa, based on parsimony analyses of the matK/trnK and ITS dataset. Besides, R. carpaticus has been revealed as distinct species and was included in the same subgroup with $R$. montanus, $R$. villarsii, $R$. pollinensis, and $R$. gouanii.

The principal coordinate analysis (PCoA) based on the Jaccard dissimilarity coefficient confirmed the number of clusters revealed by UPGMA cluster analysis (Fig. 4). Substantial dispersion of Ranunculus accessions in the PCoA plot suggests a high diversity amoung the these species. 


\section{Conclusions}

To the best of our knowledge, SRAP markers were used for the first time in this study to analyze genetic diversity within the Ranunculaceae family. The results provide deeper understanding of the genetic diversity and evolutionary relationships of the above-mentioned Ranunculus species and might be a useful tool for plant breeding and conservation purposes. UPGMA cluster analysis showed that most of the accessions from the same species tended to have high genetic similarity and clustering into the same groups or subgroups. $R$. polyanthemos and $R$. repens were found to be the most closely related species, while $R$. acris has been revealed as a distinct taxon. Finally, the use of more accessions in different species might lead to more insightful results.

Acknowledgments. This research work was partly supported by the PN-II-PT-PCCA2013-2014, project no. 168/2014 GERMPLUM and through a program of Ph.D. research fellowship.

\section{References}

1. Alexan M, Bojor O, Craciun F (1991). Flora Medicinală a Romaniei, 2th edn. Ceres Publ., Bucuresti, pp. 23-41.

2. Budak H, Shearman RC, Parmaksiz I, Gaussoin RE, Riosdan TP, Dweikat I (2004). Molecular characterization of buffalograss germplasm using sequence-related amplified polymorphism markers. Theoretical and Applied Genetics, 108(2):328-334.

3. Cai-fan Y, Sheng-wei L, Min C, Ming-feng J, Yi L, Yongfang X, Quan S, Huai-zhong J, Neng-wen Y, Ling W, Rui Z, Cheng-lin H, Kairong L (2010). Molecular phylogeny of Ranunculaceae based on rbc L sequences. Biologia 65 (6):997-1003.

4. Chung KS, Byoung-Un O, Myung SP, Bo MN, Gyu Y (2013). Chromosome numbers of 28 taxa in 10 genera of the Ranunculaceae (Buttercup Family) from the Korean Peninsula. Caryologia, 66(2):128-137.

5. Cristea V (2007). Plante Vasculare: Diversitate, Sistematica, Ecologie si Importanta. Presa Universitara Clujeana Publ., Cluj Napoca, pp. 32-38.

6. Dochev G, Zhalnov I, Docheva M (2014). Ecologicalanatomical characteristic and volatility of Ranunculus arvensis var . spinosus, genus Ranunculus L. (Ranunculaceae Juss) Turkish Journal Of Agricultural and Natural Sciences, 2:1464-1467.

7. Emadzade K, Lehnebach C, Lockhart P, Hörandl E (2010). A molecular phylogeny, morphology and classification of genera of Ranunculeae (Ranunculaceae). Taxon. 59(3):809-828.

8. Fischer M, Husi R, Prati D, Peintinger M, Van Kleunen M, Schmid B (2000). RAPD variation among and within small and large populations of the rare clonal plant Ranunculus reptans (Ranunculaceae). American Journal of Botany, 87(8):1128-1137.

9. Florence N, Machon N, Porcherm E (2007). No genetic diversity at molecular markers and strong phenotypic plasticity in populations of Ranunculus nodiflorus, an Endangered plant species in France. Annals of Botany 99: 1203-1212.

10. Hamrick JL and Godt MJW (1996). Effects of life history traits on genetic diversity in plant species. Philosophical Transactions of the Royal Society B: Biological Sciences 351:1291-1298.

11. Hao DC, Xiao PG, Ma HY, Peng Y, He CN (2015). Mining chemodiversity from biodiversity: Pharmacophylogeny of medicinal plants of Ranunculaceae. Chinese Journal of Natural Medicines. 13(7): 507-520.

12. Heywood VH, Brummitt RK, Culham A, Seberg O (2007). Flowering Plant Families of the World. Firefly Books. Ontario. pp 273-276.

13. Hörandl E, Paun O, Johansson JT, Lehnebach C, Armstrong T, Chen L, Lockhart P (2005). Phylogenetic Relationships and evolutionary traits in Ranunculus s.l. (Ranunculaceae) inferred from ITS sequence analysis. Molecular Phylogenetics and Evolution 36 (2): 305-327.

14. Idrees M and Irshad M (2014). Molecular Markers in Plants for Analysis of Genetic Diversity: A Review. European Academic Research 2(1):1513-1540.

15. Inceer $\quad H$, Hayirlioglu-Ayaz S, Ozcan M (2007). Chromosome numbers of the twenty-two turkish plant species. Caryologia 60 (4):349-357.

16. Li G and Quiros CF (2001). Sequence-related amplified polymorphism (SRAP), a new marker system based on a simple PCR reaction: its application to mapping and gene tagging in Brassica. Theoretical and Applied Genetics, 103(2-3):455-461.

17. Li G, McVetty PBE, Quiros CF (2013). SRAP molecular marker technology in plant science. Plant Breeding from Laboratories to Fields, pp. 23-43.

18. Lodhi MA, Ye GN, Weeden NF, Reisch BI (1994). A simple and efficient method for DNA extraction from grapevine cultivars Vitis species. Plant Molecular Biology Reporter, 12(1):6-13.

19. Mantel NA (1967) The detection of disease clustering and a generalized regression approach. Cancer Res. 27:209220.

20. Nei M and Li WH (1979). Mathematical model for studying genetic variation in terms of restriction endonucleases. Proc Natl Acad Sci. USA 76:5269-5273.

21. Paun O, Lehnebach C, Johansson JT, Lockhart P, Hörandl E (2005). Phylogenetic relationships and biogeography of Ranunculus and allied genera (Ranunculaceae) in the mediterranean region and in the european alpine system. Taxon 54 (4):911-930.

22. Pop R, Ardelean M, Pamfil D, Gaboreanu IM (2003). The efficiency of different DNA isolation and purification in ten cultivars of Vitis vinifera. Bulletin USAMV Biotechnology, 59:259-261. 
23. Rao VR and Hodgkin T (2002). Genetic diversity and conservation and utilization of plant genetic resources. Plant Cell, Tissue and Organ Culture 68:1-19.

24. Rohlf FJ (2000). NTSYS-pc: numerical taxonomy and multivariate analysis system. Exeter Publ, Setauket, NY.

25. Săvulescu E (2010). Botanica Sistematica. Printech Publ., Bucuresti, pp. 44-48.

26. Suranto $S$ (2002). Cluster analysis of Ranunculus species. Biodiversitas, Journal of Biological Diversity 3:201-206.

27. Talebi M, Kazemi M, Sayed-Tabatabaei BE (2012). Molecular diversity and phylogenetic relationships of
Pistacia vera, Pistacia atlantica subsp mutica and Pistacia khinjuk using SRAP markers. Biochemical Systematics and Ecology 44, 286 179-85.

28. Tămaş M (2005). Botanică Farmaceutică: SistematicaCormobionta. Vol. III. Cluj Napoca: Medicală Universitară.

29. Zhang X, Zhang F, Zhao H, Guan Z, Chen S, Jiang J (2014). Comparative analysis of genetic diversity among species of Chrysanthemum and its related genera using InterSimple 291 Sequence Repeat and Sequence-Related Amplified Polymorphism Markers 13(4):8469-8479. 